\title{
Estimation of Partition Coefficients of Benzene, Toluene, Ethylbenzene, and $p$-Xylene by Consecutive Extraction with Solid Phase Microextraction
}

\author{
In-Yong Eom \\ Department of Life Chemistry, College of Natural Science, Catholic University of Daegu, Gyeongsan 712-702, Korea \\ E-mail: einyong@cu.ac.kr \\ Received January 21, 2011, Accepted March 29, 2011
}

Key Words : Partition Coefficient, Solid phase microextraction, Consecutive extraction, BTEX, Excel-solver

It is very important to use partition coefficients of organic pollutants to predict their fate in the environment. A liquidliquid extraction technique was used to determine the partition coefficients of organic compounds between water and organic solvent. ${ }^{1}$ The concentration of the target compounds must be determined after equilibrium is established between the two phases. The partition coefficients can be estimated using the capacity factors of HPLC and GC..$^{2-4}$

The solid phase microextraction (SPME) technique has been widely used for the analysis of volatile organic compounds (VOCs) in water and air; fragrances in perfume, food, and cosmetics; and many other emerging pollutants. In addition, the fact that SPME extraction is based on equilibrium drove scientists to develop a new approach to determine partition coefficient $\left(K_{\mathrm{d}}\right)$ values. Vaes et al. used the kinetics of partitioning to SPME fibers to estimate the $K_{\mathrm{d}}$ values for 19 organic compounds. ${ }^{5}$ Nardi used the "depletion technique" and a capillary tubing coated with siloxane to estimate the $K_{\text {ow }}$ values of BTEX. ${ }^{6}$ The $K_{\mathrm{d}}$ values of hydrophobic compounds are generally known to have a close relationship with $K_{\text {ow. }}{ }^{7}$ Dean and colleagues showed a close correlation between water-fiber coefficients $\left(K_{\mathrm{fs}}\right)$ and octanol-water partition coefficients $\left(K_{\text {ow }}\right){ }^{8}$ All these approaches use an absolute amount of analyte extracted from the SPME fiber. The liquid injection of a known amount of standard solution is a common technique to calibrate GC for quantitative analysis with the SPME fiber. This technique assumes that the sample transfer efficiency by the SPME fiber is the same as that of liquid injection. However, this study shows that several factors need to be considered in order to achieve higher sample transfer efficiency in the case of liquid injection, ${ }^{9}$ i.e., the liner, glass wool, and the temperature of the injector. The difference in sample transfer efficiency between liquid injection and the SPME fiber may result in errors in the estimation of $K_{\mathrm{fs}}$ values, i.e., $K_{\mathrm{ow}}$ values.

In this study, water-fiber partition coefficients $\left(K_{\mathrm{fs}}\right)$ were determined from consecutive extraction data by a SPME fiber. Instead of using the absolute mass of the analyte, the relative GC signal ratio was used to estimate the partition coefficients. An SPME fiber extracts target compounds multiple times from the same sample vial and inserts the fiber into a hot GC injector. The extracted amount on the fiber coating decreases exponentially after each extraction; $K_{\mathrm{fs}}$ of an analyte can be derived from the resulting GC responses.
Theory. The following is the equation showing the relationship among the extracted amount (n, the number of moles of the analyte with an initial concentration of $C_{o}$ ), the extraction phase volume, $\left(V_{f}\right.$, typically $\left.0.6 \mu \mathrm{L}^{10}\right)$, and the sample volume $\left(V_{s}\right)$ when an SPME fiber has reached equilibrium with the analyte. Eq. (1) shows that the extracted amount is governed by the partition coefficient $\left(K_{\mathrm{fs}}\right)$ of the target analyte:

$$
n=\frac{K_{f s} V_{f} V_{s} C_{o}}{K_{f s} V_{f}+V_{s}}
$$

From a consecutive extraction, the extracted amounts of an analyte on the fiber coating can be expressed as $n_{1}$ and $n_{2}$ after the $1^{\text {st }}$ and $2^{\text {nd }}$ extractions as below:

$$
\begin{aligned}
& n_{1}=\frac{K_{f s} V_{f} V_{s} C_{o}}{K_{f s} V_{f}+V_{s}} \\
& n_{2}=\frac{K_{f s} V_{f} V_{s} C_{1}}{K_{f s} V_{f}+V_{s}}
\end{aligned}
$$

$C_{1}$ is the concentration of the analyte after the first extraction, and it can be expressed as $C_{1}=C_{o}-\left(n_{1} / V_{s}\right)$. We can derive eq. (4) by dividing eq. (3) by eq. (2) and subsequently replace $C_{1}$ with $C_{\mathrm{o}}-\left(n_{1} / V_{s}\right)$ :

$$
\frac{n_{2}}{n_{1}}=1-\frac{K_{f s} V_{f}}{K_{f s} V_{f}+V_{s}}
$$

Finally, eq. (4) can be expressed in a general form as eq. (5) below, where $n(i)$ and $n(j)$ are the extracted absolute moles of the target analytes of the $\mathrm{i}^{\text {th }}$ and $\mathrm{j}^{\text {th }}$ extractions, respectively. The subscripts $j$ and $i$ are integers, and $j$ must be equal to or larger than $i$.

$$
\frac{n(j)}{n(i)}=\left[1-\frac{K_{f s} V_{f}}{K_{f s} V_{f}+V_{s}}\right]^{(j-i)}
$$

GC signals have a linear relationship with this extracted mass; as a result, these signals are directly used instead of the mass term of $n(j) / n(i)$. We do not need the absolute amount of $n(j)$ and $n(i)$ extracted on the fiber coating to get the $n(j) / n(i)$ value, which means that we do not need to calibrate the GC with a known amount of analyte for this purpose. Instead, we can get the $n(j) / n(i)$ value using the GC signals, i.e., $n_{2} / n_{1}=S_{2} / S_{1}$, where $S_{1}$ and $S_{2}$ are the GC responses after the $1^{\text {st }}$ and $2^{\text {nd }}$ extractions, respectively. The sample volume $V_{s}$ can be chosen $(10.0 \mathrm{~mL}$ in this study) and 
$V_{f}$ is fixed as $0.6 \mu \mathrm{L}$, and consequently, the partition coefficient $\left(K_{\mathrm{fs}}\right)$ can be calculated directly from eq. (5). Alternatively, eq. (5) can be used as the model equation to get the best-fit values $\left(K_{\mathrm{fs}}\right)$ using Microsoft Excel Solver. ${ }^{11}$

A polydimethylsiloxane (PDMS)-coated SPME fiber (100 $\mu \mathrm{m}$ thickness) was purchased from Supelco. Ten-milliliter amber vials with screw caps and PTFE-coated silicone septa were used. Benzene, toluene, ethylbenzene, and $p$-xylene (BTEX) were purchased from Sigma-Aldrich. A methanolic BTEX standard mixture (100 ppmv) was prepared by taking $10 \mu \mathrm{L}$ of the pure liquid phase and diluting each one of them with $100 \mathrm{~mL}$ of pure methanol. A working solution (12.5 ppbv) was prepared by spiking $1.25 \mu \mathrm{L}$ of the BTEX standard mixture into $10 \mathrm{~mL}$ of deionized water in a $10-\mathrm{mL}$ screw cap vial. A Teflon magnetic stirrer (1 cm long) was inserted in the vial to stir the solution and thus to enhance sample transportation toward the SPME fiber coating from the bulk solution. Then, the vial was kept at $30^{\circ} \mathrm{C}$ on a temperature programmable hot plate. For BTEX extraction, first, the PDMS SPME fiber needle was inserted by piercing the septum, and then, the fiber was inserted into the aqueous BTEX solution. The extraction time was $3 \mathrm{~min}$, which is sufficient for the BTEX component to attain equilibrium with the extraction phase. After extraction, the fiber was withdrawn, removed from the vial, and then inserted into a hot $\mathrm{GC}$ injector $\left(250^{\circ} \mathrm{C}\right)$ to analyze the extracted components on the fiber. As the fiber was inserted into the hot GC injector, the BTEX components on the fiber were thermally desorbed fast, owing to the injector's high temperature; then, their components were transported to a separation column under the splitless injection mode. Gas chromatography was carried out on an Agilent 6890 gas chromatograph (Youngin Sci, Seoul, Korea) with a flame ionization detector (FID) equipped with an HP-5 separation column $(30 \mathrm{~m} \times 0.32 \mathrm{~mm}$ I.D., $0.25 \mu \mathrm{m}$ thickness). The column was initially set to 40 ${ }^{\circ} \mathrm{C}$ for $1.5 \mathrm{~min}$, ramped to $120^{\circ} \mathrm{C}$ at a rate of $25^{\circ} \mathrm{C} / \mathrm{min}$, and then held at this temperature for $0.3 \mathrm{~min}$ for a total run time of $5 \mathrm{~min}$. The injector was set to $250{ }^{\circ} \mathrm{C}$ and the desorption time was $2 \mathrm{~min}$. The carrier gas (helium) was set at a constant flow of $1 \mathrm{~mL} / \mathrm{min}$. The same procedure was repeated 6 times; that is, 7 extractions were performed consecutively with the same BTEX solution.

Extraction Data Curve. As can be seen in Figure 1, the GC responds gradually (actually exponentially, which is not clearly visible in this figure) decreases as more number of extractions is performed. The $\mathrm{y}$-axis is the relative GC response normalized to the first GC response. Eq. (5) is used as the model equation and the best-fit values for the partition coefficient $\left(K_{\mathrm{fs}}\right)$ are obtained using Excel Solver, which is based on the consecutive extraction data (Fig. 1). The calculated $K_{\mathrm{fs}}$ and the referenced $K_{\text {ow }}$ values are listed in Table 1. All $\log \left(K_{\mathrm{fs}}\right)$ values for BTEX determined remain in the same order of magnitude as the $\log \left(K_{\text {ow }}\right)$ values, which is remarkable because of the disagreement among the multitude of $K_{\mathrm{d}}$ values reported by different authors even for the same compound. The dotted and solid curves in Figure 1 are drawn using the calculated partition coefficients.

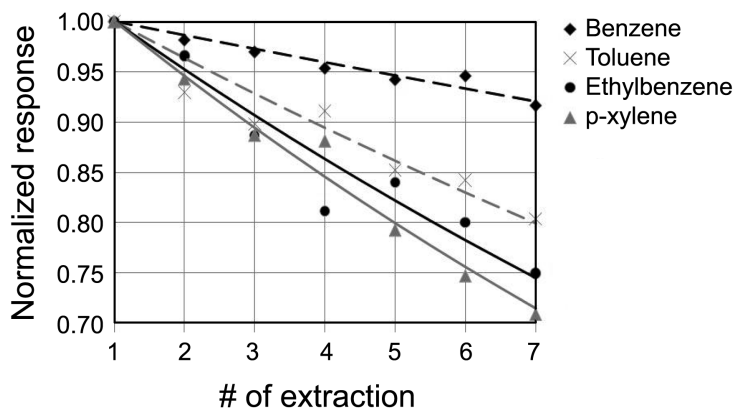

Figure 1. Consecutive extraction data of BTEX mixture with a $100-\mu$ M PDMS SPME fiber.

Table 1. Comparison between $\log \left(K_{\text {ow }}\right)$ and $\log \left(K_{\mathrm{fs}}\right)$

\begin{tabular}{ccccc}
\hline & Benzene & Toluene & Ethylbenzene & $p$-Xylene \\
\hline $\log K_{\mathrm{fs}}$ & 2.37 & 2.80 & 2.92 & 2.98 \\
$\log K_{\text {ow }}$ & $2.13^{6}$ & $2.69^{13}$ & $2.84^{14} 3.15^{13}$ & $3.15^{5}$ \\
\hline
\end{tabular}

In conclusion, the results show that the partition coefficients of the BTEX compound can be estimated using the SPME method under the consecutive extraction mode. The proposed technique is much simpler than previously reported methods. ${ }^{5,6,8}$ Its novelty is that it eliminated the calibration step in the GC/FID, i.e., liquid injection method. The use of the autosampler ${ }^{12}$ for the SPME fiber can facilitate the adoption of consecutive extractions; thus, it allows estimation of the partition coefficients of various analytes. Recently, GC/MS has increasingly been used in analytical laboratories; this may facilitate the identification of an unknown analyte as well as the computation of the corresponding partition coefficients with the proposed method.

Acknowledgments. This work was supported by research grants from the Catholic University of Daegu in 2010.

\section{References}

1. Qiao, S.; Xia, S.; Ma, P. J. Chem. Eng. Data 2008, 53, 280.

2. Paschke, A.; Neitzel, P. L.; Walther, W.; Schüürmann, G. J. Chem. Eng. Data 2004, 49, 1639.

3. OECD Guideline for Testing of Chemicals No. 117, Partition Coefficient ( $n$-Octanol/water), HPLC Method, OECD, Paris, 1995.

4. Revelli, A.-L.; Mutelet, F.; Jauber, J.-N. J. Chromatogr. A 2009, $1216,4775$.

5. Vaes, W. H. J.; Hamwijk, C.; Ramos, E. U.; Verhaar, H. J. M.; Hermens, J. L. M. Anal. Chem. 1996, 68, 4458.

6. Nardi, L. J. Chromatogr. A 2003, 985, 39.

7. Poerschmann, J.; Zhang, Z.; Kopinke, F.-D.; Pawliszyn, J. Anal. Chem. 1997, 69, 597.

8. Dean, J. R.; Tomlinson, W. R.; Makovskaya, V.; Cumming, R.; Hetherridge, M.; Comber, M. Anal. Chem. 1996, 68, 130.

9. Ouyang, G.; Chen, Y.; Setkova, L.; Pawliszyn, J. J. Chromatogr. A 2005, 1097, 9.

10. Bicchi, C.; Iori, C.; Rubiolo, P.; Sandra, P. J. Agric. Food Chem. 2002, 50, 449.

11. Walsh, S.; Diamond, D. Talanta 1994, 41, 561.

12. http://www.atasgl.com/pal/pal_about.html.

13. Chiou, C. T. Envirion. Sci. Technol. 1985, 19, 57.

14. Chiou, C. T.; Schmedding, D. W.; Manes, M. Environ. Sci. Technol. 1982, 16, 4. 